\title{
Reading Disability as a Condition of Family Stability
}

\author{
DANIEL R. MILLER, Ph.D.
}

JACK C. WESTMAN, M.D. ${ }^{\mathrm{a}}$

aUniversity of Michigan, Ann Arbor, Michigan. This research has been supported by Mental Health Project Grant MH-1045-1 of the National Institutes of Health. The authors are indebted to Bettie Arthur, William Bell, Eric Bermann, Alan Fontana, Etta Saxe, Sarah Slagle and Richard Wagner for their help in collecting the data.

To explain a psychogenic symptom like retarded reading, clinicians typically adopt one of two positions. Traditionally, they have regarded it as a substitute for conflicting impulses, but in recent years a number of authors $(1,3,4,7,8,11,12$, 13) have concentrated on the vicarious satisfaction the symptom provides one or both parents and have shown how it is supported by collusive arrangements among members of the family. Just where internal dynamics fit into the interpersonal picture is a point on which these authors tend to differ.

Our initial observations of children with functional retardation in reading convinced us that an etiological study would require information about both internal dynamics and family relationships and would confront us with the knotty problem of defining associations between the two kinds of analysis. But even before we could think about these associations it became necessary for us to define the concepts required for the phrasing of questions, there being no commonly accepted terminology for describing the properties of social relationships.

In describing the provisional results of our study we begin with an account of our methods, following which we summarize some representative findings about the internal dynamics of children and parents. After defining terms such as stability, compatibility, bond, and subidentity, which we found most helpful in thinking about the data, we conclude the paper with observations about relationships and their connections with retarded reading. We separate data about the individual from data about his relationships to contrast the kinds of insight each contributes to the origin and maintenance of symptoms.

\section{METHODS}

Our subjects were 18 boys who were outpatients at Children's Psychiatric Hospital, a unit of the University of Michigan Medical Center. To be chosen for the study a boy had to be between 10 and 12 years of age, within the normal range on nonverbal tests of intelligence, retarded at least two years in reading level, lacking in visual or neurological pathology, not psychotic, and from an intact, white family in either the middle or working class. All the subjects had received, but had not profited from, intensive coaching in the basic skills of reading. Our conclusions can only be generalized, therefore, to boys who have not benefited from special coaching and need psychiatric treatment. This is an important qualification, the significance of which will be discussed later in the paper.

The children were given physical and neurological examinations, a diagnostic interview, the Stanford-Binet or Wechsler Bellevue Test of intelligence, a battery of reading tests, the Rorschach Test, the Thematic Apperception or Children's Apperception Test, and other techniques appropriate to the individual patient. To obtain the parents' conscious versions of events, we employed a questionnaire and check list covering the history of the reading problem, reasons for seeking help, and descriptions of experiences with different members of the family. To learn about the parents' preconscious and unconscious conceptions, we employed the Thematic Apperception Test, a projective test of defense mechanisms, an unstructured interview and a semi-structured interview about marital, parental, occupational, social, and homemaking activities.

Data were also drawn from individual, weekly, psychotherapeutic sessions with each child and his parents, and periodic visits to the home and school. The findings to be reported are those on which the families in the sample differed from a control group matched on all criteria except the primary complaint.

\section{DYNAMICS AND BEHAVIOR}

First we describe the children, fathers and mothers as individuals. The children's clinical reports reveal a marked tendency toward withdrawal from frustrating situations by substituting fantasies of omnipotence for the world of reality, frequent projection and introjection of oral-sadistic impulses in encounters with parents, and a biting of verbal material that interferes with its integration into meaningful sequences. A typical patient often put his fingers in his mouth, asked for candy, and spoke of being hungry. In his speech he "chewed up" certain words; "chine," for example, was substituted for machine.

In relating to adults, most of the boys are cautious, fearful, conforming, and verbally self-demeaning, but they frequently 
alternate between their usual protestations of inadequacy and a subtle, passive resistance that verges on needling. When asked how a Rorschach card reminded him of a butterfly, a boy in an ungraded class replied, "I think I saw one like it before." When asked what that butterfly had looked like, he answered with wide-eyed innocence, "It looked very good."

Accompanying this resistance is a surprising equanimity about a symptom that is creating serious educational difficulties and is the subject of considerable pressure by parent, teacher, social worker, and remedial teacher. In fact, most boys become upset at the prospect of losing the symptom; they typically become more inept with verbal material or acquire new problems. Not long after one boy's progress in reading had been described glowingly in a report card, he began to attack younger children viciously, usually in ways that were guaranteed to be observed or discovered by adults. Just as the principal was passing by, for example, the boy once hit a child in the face with a hard packed snowball from a distance of two feet. It was not long before these attacks were the subject of conferences among the same adults who had met previously to consider the boy's poor performance in reading.

Side by side with the children's many regressive traits are important assets. One is the ability to read more proficiently than is indicated by performance. The variations in some of the patients' reading levels suggest that the problem is one of inhibited rather than retarded reading. The children are typically sensitive, good-looking, potentially above average in intelligence, fairly successful in attracting friends, and capable of realistic social adjustments except in activities pertaining to scholastic achievement. Rare in the sample are the symptoms so characteristic of patients in a psychiatric hospital- the phobia, the obsession, the antisocial acting out.

Most of the children seem split into at least three major identities. One might be described as a frightened, cautious, daydreaming, asexual, and pseudo-stupid baby; the second as an omnipotent, manipulative, dominant, needling and sadistic adolescent; the third as a socially adequate, bright, confident, but overburdened, premature adult. These splits are resolved by projections of unacceptable parts to the parents (6). The frightened asexual baby is typically attributed to the father, and the omnipotent, sadistic adolescent to both parents. As will be indicated, the child, usually the best judge of reality in the family, often provides the ballast necessary to keep the marital enterprise on an even keel.

The sons' projections find fertile ground in the parents' actual identities. Many of the fathers tend to be dominating, even threatening, but because of an underlying lack of confidence, they are ineffectual and easily manipulated by wives and offspring. Many are the signs of inadequacy these men betray. Some suffer from partial or total sexual impotence, some from severe homosexual conflicts. At home, a number pursue a solitary hobby in the garage or basement with such enthusiasm they have little or no time for family or friends.

Plagued by educational problems in childhood, most of the fathers have attained an occupational status considerably below their potential. Handicapped, too, by such problems as the inability to tolerate intimate relationships or to accept supervision, most of the men have drifted into poorly paying routine jobs entailing such duties as making small repairs in private homes, selling at a low rate of commission, manual labor, or semi-skilled clerical work. In most families, at least one parent is in a lower social class than that of his or her parents. The women commonly complain about economic hardship and the necessity of depriving their children of clothing and commodities available to other children in the neighborhood.

Despite these difficulties, most of the fathers appear confident, indeed assertive. This facade on the level of consciousness is typically maintained by such defenses as denial of difficulties, projection of weaknesses to others in the family or of hostility to outsiders, withdrawal from social contacts which might interfere with the denial or projection, and an interpretation of events that leads to a feeling of omnipotence. Some fathers' hold on reality is so tenuous as to suggest the diagnosis of borderline psychosis. To buttress the mutual denial of the fathers' pathology and other difficulties, some families have relinquished non-occupational contacts with most outsiders, often giving the reasonable excuse that their income is insufficient for a rich social life.

The mothers are viewed by their sons, again correctly, as having the power in the family, and as non-nurturant, controlling and seductive. Many of the women are relatively realistic, but they typically keep their thoughts to themselves to avoid challenging their husbands' omnipotent and persecutory ideas. Also unexpressed is the guilt many wives feel because of the exploitation of husband or son, and the low self-esteem which may be caused by feeling stupid or inept or by deprecation of their own femininity. Some of the women give their husbands emotional support as long as they do not make the decisions that really count in the home. A representative wife made the economic decisions in the family, was sexually unresponsive to her husband, coached him in the attitudes she wanted him to express to his therapist, and depreciated him covertly to her son and overtly to her therapist. Phallic and sadistic tendencies were characteristic of her responses to projective tests.

\section{TERMINOLOGY FOR ANALYZING RELATIONSHIPS}

Although these findings shed light on the disturbances of fathers, mothers, and children as individuals they do not adequately answer two major questions: why is the reading problem so refractory to treatment? and why did the children develop this symptom rather than some other? Much of the missing information is supplied by the study of relationships. To 
interpret them, a special set of terms was needed (10). In the tradition of Cooley (2) and Mead (4) we analyze relationships in terms of the participants' awareness of each other's identities, their picture of themselves, and their attempts to satisfy their individual and mutual needs in a manner compatible with an acceptable level of self-esteem. We divide each person's total identity into subidentities, some of which are normal and some pathological. The normal subidentities are organized within the limits set by primary roles. Unlike role, which is defined by the expectations of others, a subidentity is a cluster of traits experienced as part of the self. Abnormal subidentities may be splits in the normal ones created by pressure to behave in contradictory ways, or regressive subidentities from earlier stages of development.

The primary questions we ask about relationships pertain to their sources of stability. From one point of view, stability is the strength of the forces holding a couple or a family together; from another, it is the resistance of the relationship to dissolution. Stability is inferred from the compatibilities or fits between various kinds of pressure in the relationship. We distinguish three types: 1) externally induced pressures on each person, such as others' expectations that he meet his obligations, or the projections of others, which prompt him to blame himself; 2) internally induced pressures, such as needs and values; and 3) barriers to action, such as role proscriptions and mutual denial.

Of the interpersonal units that we code, the bond, the primary building block of relationships, represents the greatest compatibility between the internally induced pressures of the partners. A bond is a mutual tendency of two people to engage in particular activities, and occurs when the traits of one person's subidentity gratifies the other person's needs. A bond exists, for example, when one person enjoys being the learner and the other enjoys being the teacher.

\section{RELATIONSHIPS WITHIN THE FAMILIES}

Observation of relationships has persuaded us to view the meaning of retarded reading in the context of the child's subidentity as pseudo-stupid or infantile son. The symptom is thus an essential ingredient in the bonds between his subidentity and the parental subidentities of father and mother and often helps to maintain bonds between the parents' marital subidentities. In short, we postulate that parents and children resist change in the reading disability because it contributes to the family's survival.

What facts can one collect in support of such an interpretation? We have been gathering four kinds of evidence: 1) that the child's symptom and subidentity are compatible with those of the parents; 2) that members of many families engage in activities which reinforce the symptom; 3) that concrete evidence of the child's unrealized intellectual potential is denied by the adults and even the child; 4) that some members react to improved reading with emotional disturbances, and the entire family responds as it would to a major emergency.

To evaluate compatibility we did blind analyses of the subidentities revealed during the diagnostic period by father, mother and son. Then we estimated the fit of traits that pairs of people would probably employ reciprocally in situations related in some way to the symptom. There is not sufficient space to illustrate the many patterns of compatibility, such as the mutual projection of blame to the school, or the complex pairings of traits in which the father is consciously powerful but unconsciously impotent and the son consciously deferent but unconsciously dominant. Three of the commonest patterns deserve mention here. In one the son's symptom and subidentity enable the parents to employ the defenses they need for their personal equilibrium. One father retained a conscious subidentity as genius by projecting his unconscious subidentity as moron to his son. The boy's subidentity as moron was also needed by his mother. Although consciously passive, she could not tolerate competence in either of her men, and obtained a reassuring unconscious sense of power from helping both to compensate for their weakness. In return for the boy's acceptance of his parents' projections, he gained certain illicit gratifications: a sexualized relationship with his mother, a sense of omnipotence because of his power to damage his parents, the opportunity to bait them, and even occasional bribes. All of these were lost when he improved in reading. It is not surprising, then, that he was reluctant to change.

In another pattern, the symptom and subidentity act as governors on aggression between the parents. When their attacks on each other reach a threshold, both parents displace their aggression to their son, using the reading as the object of their concern. The mutual attack on the symptom serves as a bond that holds them together, helps them to concentrate on the loving parts of their marital subidentities, and provides the son with masochistic gratification.

In a third pattern, which overlaps with the other two, the father and son, in their subidentities as offspring, engage in a continual struggle with each other for dominance and for the mother's parental attention. Enabled by the son's pseudo-stupid subidentity to gain an apparent victory, the father presses his advantage by means of many depreciating actions. Unconsciously both recognize that the son has actually won an Oedipal victory; if he relinquishes his pseudo-stupidity, he can destroy his father.

As for reinforcement of the symptom, the second type of evidence, the most common method is coaching under conditions that are bound to bore the child or make him fail. Each afternoon, one of the mothers helped her son with his homework in front of a television screen; the set was turned on so the father could enjoy the antics of Bugs Bunny. Another father, gratified by his son's enthusiasm on seeing his first hockey game, bought him a complete hockey outfit, dressed him in it, took him to a rink and gave him a three hour lecture on the niceties of the game. The boy would not don his skates for 
some years.

When one boy failed in school, he was coached by an impatient, punitive father and deprived of all privileges such as parties during Christmas vacation and the opportunity to look at television. So bitter and upset was he that his performance at school deteriorated even further.

The denial of objective evidence of normal intelligence, the third type of evidence linking the symptom to familial stability, occurred in virtually all families. One boy called himself a moron despite this information; most of the boys protested that they were not very bright. Some parents acted as though they had not heard the report and later repeated their assumptions about intellectual deficit; some said their sons were backward but would still get along in life; a few expressed disbelief; none acted gratified.

The most vivid evidence in support of the thesis is provided by reactions to change, the fourth type of evidence. Many parents denied or reacted with consternation to information that their sons had made progress in reading. One mother said that she must be losing her mind. She had always wanted her son to read well, but whenever she thought of his recent progress she broke into tears. Her husband on learning of the boy's improvement stopped working and began to show unmistakable psychotic symptoms. Following another boy's rise in reading level, his mother started an argument with his father, who beat her up and left home. She became severely depressed and neglected her family. So distressed was the child that he did no work at school, and his ability to read deteriorated markedly. His father then returned, his mother lost her depression, and the family continued as before.

Learning of a son's improvement, his parents began to punish him drastically for misbehavior they had previously ignored. He continued to do good work at school, but started to stay away from home whenever he could. They then made another brother the object of the same tactics which had contributed to his sibling's retarded reading.

\section{COMPLAINTS, OFFICIAL AND UNOFFICIAL}

The postulated connection between the symptom and stability raises a paradoxical problem. If the child's retardation in reading is required for the family's stability, wouldn't one expect his parents to avoid treatment? The paradox is resolved by three findings. First, referral to the clinic has usually been suggested by the school years before the family actually seeks help. Second, after therapy begins, the parents and the children rarely mention the symptom. In fact they may react to persistent inquiry into the symptom by stopping therapy. Third, one or more members of the family typically persists in talking about a topic unrelated to the official complaint. Usually the topic is a problem the members of the family cannot solve among themselves; sometimes they cannot even discuss it without serious conflict. Plagued by this unofficial problem which has markedly decreased familial stability, the parents are forced to seek help from outsiders. Because they are able to agree that the reading difficulty is a problem, they use it as a vehicle for obtaining assistance with the more serious source of instability.

Many are the instances we have recorded of family emergencies having nothing to do with the son's scholastic performance being followed by intensive parental campaigns to do something about his reading. In one family, for example, the unofficial problem was a truly mentally defective adolescent son who was attacking younger children. Finding that the father denied the son's obvious handicap and his need for institutional care, the anxious mother soon became worried about his brother, the nonreader in the family, and insisted on following a previous recommendation of psychiatric treatment. Once the defective son was institutionalized, the parents lost interest in the treatment of his nonreading brother.

Another family's unofficial problem was a daughter's sexual promiscuity which, because it provided the parents with vicarious sexual gratification, was abetted by the mother, tolerated by the father, and denied by both. When the promiscuity became flagrant, the father tried to discuss it with his wife, but she continued to deny it and to facilitate the daughter's sexual activities. Finding himself ignored by the females in his family, the father became very concerned about his son's poor school work and sought treatment at the clinic.

Sometimes the covert problem is the only factor that prompts the family to come for help. In one working class family the wife initiated the request for treatment to get help in eliminating a competitor who was ensconced in the marital bed. A husband who sought help was upset because his mother-in-law had just moved in and was turning his wife and son against him. Both families resisted discussion of the reading problem; when relieved of the unofficial source of difficulty, both quit therapy.

As for the reasons why the child develops a reading problem rather than some other symptom, we have only some tentative guesses. Notable in the families is the large proportion of parents who had trouble with reading and other scholastic subjects when they were in elementary school. Difficulties in reading, then, are a natural arena in which the parents can work out conflicting relationships with the children. A second characteristic of many parents, the inclination to favor denial of problems, may reinforce a tendency to avoid "seeing" disturbing material—seeing having both the meanings of looking and understanding. Some of the boys have gotten into difficulty at home because they were the only ones who did see disturbing facts; for example, the boy who labelled his sister's sexual activities for what they were in the face of his parents' denial of the problem. 


\section{SYMPTOMS AND STABILITY}

In this paper we have tried to illustrate the different kinds of information one gets from analyzing inner dynamics and relationships, to show how a special terminology is needed for phrasing questions about relationships, and to define some of the connections between symptoms, the characteristics of relationships, and the family's stability. One final question pertains to the generalization of our findings. Are all symptoms necessary for maintaining basic relationships in the family? When children with symptoms other than the ones we have studied, such as antisocial behavior, conversions, or compulsions, begin to improve, do their parents also become as upset as the ones we observed? It is important to reiterate that we derived our conclusions from a special group of retarded readers: boys who did not profit from remedial training and became patients in a psychiatric clinic. It is also important to stress that in many of our families one parent, usually the father, is often a borderline psychotic and is able to carry on socially because of relationships which hinge on the boys' pseudo-stupid or infantile subidentities. To keep the parents from breaking down, the family acts in concert to maintain the status quo. For these reasons the symptom of severe reading retardation is often refractory to treatment.

It is likely that various symptoms differ in their contributions to a parent's equilibrium and to the bonds that maintain familial stability. Preliminary observations suggest that alloplastic symptoms, like aggressive acting out, are intimately tied to the family's stability, and that autoplastic symptoms are not. Regardless of the symptom, we find it fruitful in diagnosis and therapy to consider the nature of the child's relationships within the family because of the light they throw on his capacity for change.

\section{REFERENCES}

1. Ackerman, N. W., (1958) The Psychodynamics of Family Life, New York, Basic Books.

2. Cooley, C. H., (1902) Human Nature and the Social Order, New York, Scribner.

3. Eisenstein, V. W. (Ed.), (1956) Neurotic Interaction in Marriage, New York, Basic Books.

4. Grunebaum, M. G., Hurwitz, I., Prentice, N. M. and Sperry, B. M., "Fathers of Sons with Primary Neurotic Learning Inhibitions," Amer. J. Orthopsychiat., 32, 462-472, 1962.

5. Johnson, A. M., "Factors in the Etiology of Fixations and Symptom Choice," Psychanal. Quart., 22, 475-496, 1953.

6. Klein, M., (1948) Contributions to Psychoanalysis London, Hogarth.

7. Liss, E., "Motivations in Learning," Psychoanal. Stud. Child, 10, 100-116, 1955.

8. Mahler-Schoenberger, M., "Pseudo-imbecility: A Magic Cap of Invincibility," Psychoanal. Quart., 11, 149-164, 1942.

9. Mead, G. H., (1956) The Social Psychology of Gearge Herbert Mead, Chicago, Univ. of Chicago Press.

10. Miller, D. R., (1961) "Personality and Social Interaction," in B. KAPLAN (Ed.), Studying Personality Cross-Culturally, Evanston, Illinois, Row, Peterson.

11. Speigel, J. P. and Kluckhohn, F. R., (1956) "Integration and Conflict in the Family," Behavior Report 27, Topeka, Kansas, Group for the Advancement of Psychiatry.

12. Staver, N., "The Child's Learning Difficulty as Related to the Emotional Problem of the Mother," Amer. J. Orthopsychiat., 23, 131-140, 1953.

13. Sullivan, H. S., (1953) The Interpersonal Theory of Psychiatry, New York, Norton. 